medRxiv preprint doi: https://doi.org/10.1101/2020.11.16.20229591; this version posted November $18,2020$. The copyright holder for this preprint (which was not certified by peer review) is the author/funder, who has granted medRxiv a license to display the preprint in It is made available under a CC-BY-NC-ND 4.0 International license .

\title{
The burden of Progressive Fibrotic Interstitial lung disease across the UK
}

Thomas Simpson ${ }^{1}$, Shaney L Barratt ${ }^{2 \& 3}$, Paul Beirne ${ }^{4}$, Nazia Chaudhuri $^{5}$, Anjali Crawshaw ${ }^{6}$, Louise E Crowley $^{6}$, Sophie Fletcher ${ }^{7}$, Michael A Gibbons ${ }^{8}$, Philippa Hallchurch ${ }^{2}$, Laura Horgan ${ }^{4}$, leva Jakaityte ${ }^{8}$, Thomas Lewis ${ }^{2}$, Tom McLellan ${ }^{9}$, Ryan Miller ${ }^{8}$, Stefan Stanel $^{5}$, Muhunthan Thillai ${ }^{9}$, Fiona Thompson ${ }^{7}$, Zhe $\mathrm{Wu}^{10 \& 11}$, Philip L Molyneaux ${ }^{10 \& 11 *}$ and Alex G West ${ }^{1 *}$

*Contributed equally as last authors

Corresponding author: Dr Philip L. Molyneaux, National Heart and Lung Institute, Imperial College London, UK. E-mail: p.molyneaux@imperial.ac.uk

\section{Affiliations:}

1 Department of Respiratory Medicine, Guy's and St Thomas' NHS Foundation Trust, Great Maze Pond, London SE1 9RT

2 Bristol Interstitial Lung Disease Service, North Bristol NHS trust, Southmead Hospital, Bristol UK

3 Academic Respiratory Unit, University of Bristol, Bristol, UK

4 Leeds interstitial Lung Disease Service, St James's University Hospital, Beckett Street, Leeds LS9 7TF, UK

5 North West Lung Centre, Wythenshawe Hospital, Manchester M23 9LT, UK

6 Birmingham Interstitial Lung Disease Unit, Queen Elizabeth Hospital Birmingham, University Hospitals Birmingham NHS Foundation Trust, Birmingham, UK

7 University Hospitals Southampton NHS Foundation Trust, Southampton, UK

8 South West Peninsula ILD Network, Royal Devon \& Exeter Foundation NHS Trust, Barrack Road, Exeter EX2 5DW, UK

9 Department of Interstitial Lung Disease, Royal Papworth Hospital NHS Foundation Trust, Cambridge UK

10 National Heart and Lung Institute, Imperial College London, UK

11 Royal Brompton Hospital, UK.

Funding: PLM is supported by an Action for Pulmonary Fibrosis Mike Bray fellowship. 
medRxiv preprint doi: https://doi.org/10.1101/2020.11.16.20229591; this version posted November 18, 2020. The copyright holder for this preprint (which was not certified by peer review) is the author/funder, who has granted medRxiv a license to display the preprint in It is made available under a CC-BY-NC-ND 4.0 International license .

Abstract: While Idiopathic pulmonary fibrosis (IPF) remains the exemplar progressive fibrotic lung disease, there remains a cohort of non-IPF fibrotic lung diseases (fILD) which adopt a similar clinical behaviour to IPF despite therap. This phenotypically related group of conditions, where progression of disease is similar to that seen in IPF, have recently been described as Progressive Fibrotic Interstitial Lung diseases (PF-ILD). Previous estimates suggest that between 18 to $40 \%$ of all fILD will develop progressive disease, however, the exact burden remains unknown. This retrospective, observational study therefore aimed to estimate the incidence of PF-ILD across England.

All new referrals seen across nine UK centres for their first outpatient clinic appointment between 1st August 2017 and 31st January 2018 were assessed against the diagnostic criteria for PF-ILD laid out in the INBUILD trial. A total of 1749 patients with fILD were assessed. In this cohort of patients at risk of developing PF-ILD the INBUILD criteria were met in 14.5\% (253/1749) of all new non-IPF fILD referrals. The average time from referral to specialist centre to diagnosis of progressive phenotype was 311 days. Of the progression events the majority were driven by a measured drop in FVC, with more than half of patients experiencing a drop of $10 \%$. Almost one quarter of patients $(24.1 \%)$ were diagnosed with progressive disease on the basis of radiological and symptomatic progression alone without a spirometric deterioration.

This study represents a fair and balanced approach to assessing the incidence of objectively measurable and treatable PF-ILDs in the UK. A rate of $14.5 \%$ of new referrals with non-IPF ILD is less than that reported in previous studies however our methodology is likely to give a more accurate result than estimates based on extrapolation from general disease statistics, from physician-reported estimates prone to significant biases, or insurance claim processes also substantially prone to bias. This information has implication for workforce planning and the funding of anti-fibrotic therapy in the UK and beyond. 
medRxiv preprint doi: https://doi.org/10.1101/2020.11.16.20229591; this version posted November 18, 2020. The copyright holder for this preprint (which was not certified by peer review) is the author/funder, who has granted medRxiv a license to display the preprint in

It is made available under a CC-BY-NC-ND 4.0 International license.

To the Editor.

While Idiopathic pulmonary fibrosis (IPF) remains the exemplar progressive fibrotic lung disease, there remains a cohort of non-IPF fibrotic lung diseases (fILD) which adopt a similar clinical behaviour to IPF despite therapy [1]. This phenotypically related group of conditions, where progression of disease is similar to that seen in IPF, have recently been described as Progressive Fibrotic Interstitial Lung diseases (PF-ILD) [2]. Historically treatments for these cases have been limited and clinicians, recognising the related progression between these conditions and IPF may have been pragmatically relabelling these cases as IPF based on their disease behaviour to qualify for anti-fibrotic therapy [3]. The INBUILD trial broadened the scope of treatable fILD by demonstrating a significant benefit of Nintedanib in patients with fILD and progressive disease [4]. In response to this the European Commission (EC) approved an additional indication for Nintedanib in adults for the treatment of PFILD in July 2020.

While research interest grows in the progressive phenotype and debates about the optimal diagnostic criteria continue the incidence of patients with PF-ILD potentially eligible for treatment according to the criteria laid out in the INBUILD trial remains unclear. Previous attempts to estimate the proportion of fILD who develop a progressive fibrotic phenotype have either used estimates based on the disease behaviour of individual conditions [5], interviews with experts [6] or analysis of insurance claims [7]. This has resulted in estimates ranging from 18 to $40 \%$ of all fILD that will develop progressive disease. With the anticipated approval of therapeutic interventions for this cohort of patients worldwide, including in the UK, there is an urgent need to refine these estimates in a real-world population to enable appropriate service provision.

This retrospective, observational study therefore aimed to estimate the incidence of PF-ILD across England. Nine centres providing commissioned tertiary referral services for ILD were included. All new referrals seen for their first outpatient clinic appointment between 1st August 2017 and 31st January 2018 were assessed against the diagnostic criteria for PF-ILD laid out in the INBUILD trial [8] and in particular, the criteria for progression: relative decline in FVC $\%$ predicted $\geq 10 \%$, or FVC decline $\geq 5 \%$ but $<10 \%$, combined with worsening respiratory symptoms, or FVC decline $\geq 5 \%$ but $<10 \%$, combined with radiological progression; or radiological progression with worsening respiratory symptoms. Continuous variables are presented as means ( \pm Standard Deviation [SD]), and categorical variables as proportions.

A total of 2368 patients with fILD were assessed across the 9 centres. Six hundred and nineteen patients were diagnosed and managed as IPF and therefore excluded, leaving 1749 patients with fILD who were screened against the INBUILD criteria for progression, to identify cases of PF-ILD either at the first clinical review, or in the subsequent 2 years of follow up (Table 1). In the cohort of patients at risk of developing PF-ILD the INBUILD criteria were met in $14.5 \%(253 / 1749)$ of all new non-IPF fILD referrals, with a range between these specialist ILD centres from $8.9 \%$ to $23.6 \%$ of total cases. The average time from referral to specialist centre to diagnosis of progressive phenotype was $311( \pm 273)$ days.

The most common diagnoses associated with a PF-ILD phenotype were chronic hypersensitivity pneumonitis (84/253,33.2\%), unclassifiable ILD (44/253, 17.3\%), connective tissue disease-associated ILDs including rheumatoid arthritis-associated ILD (42/253, 16.6\%) and non-specific Interstitial pneumonitis (36/253, 14.2\%). In the PF-ILD cases, the mean age was $68 \pm 12.4$ years and interestingly $53.4 \%$ of the cohort was female, as compared to the well-recognised male predominance seen in IPF.

Of the progression events the majority were driven by a measured drop in FVC, with more than half of patients experiencing a drop of $\geq 10 \%$. Almost one quarter of patients $(24.1 \%)$ were diagnosed with 
medRxiv preprint doi: https://doi.org/10.1101/2020.11.16.20229591; this version posted November 18, 2020. The copyright holder for this preprint (which was not certified by peer review) is the author/funder, who has granted medRxiv a license to display the preprint in It is made available under a CC-BY-NC-ND 4.0 International license .

progressive disease on the basis of radiological and symptomatic progression alone without a spirometric deterioration (Table 1).

\begin{tabular}{|l|l|}
\hline INBUILD CRITERIA & $\begin{array}{l}\text { Number of cases meeting this criteria (\% } \\
\text { of PF-ILD cohort) }\end{array}$ \\
\hline Relative FVC decline $\geq 10 \%$ & $132(52.2 \%)$ \\
\hline FVC decline $\geq 5 \%-<10 \%$ with radiological progression & $40(15.8 \%)$ \\
\hline FVC decline $\geq 5 \%-<10 \%$ with symptom progression & $20(7.9 \%)$ \\
\hline Radiological and symptom progression & $61(24.1 \%)$ \\
\hline
\end{tabular}

Table 1: Determinants of progressive disease.

The variations between centres and clinicians in diagnostic pathways, approaches to follow-up and definitions of progression has previously made it difficult to define and assess this cohort of patients. One of the strengths of our approach was the central collation and uniform application of the INBUILD inclusion criteria. However, this was done retrospectively and this is the main limitation of our study. While the INBUILD trial criteria are mostly objectively measurable phenomena, the definition of progressive symptoms may allow some biasing towards inclusion in those cases where spirometric progression was either not evidenced or not available, thus increasing the numbers of cases. Over a quarter of referrals received a final multidisciplinary team (MDT) diagnosis of IPF, and this is often pragmatic and based on their clinical disease behaviour, to allow access to antifibrotic therapy. However, a patient's initial clinical and radiological features may have had more in keeping with a different ILD but with a PF-ILD phenotype. While we sought to ensure that all diagnostic labels in this study had been agreed at a local MDT, we did not at any point seek to reassess the accuracy of those labels and therefore some cases of non-IPF PF-ILD may have been missed. However, this burden of IPF is in keeping with historical data of the caseload of IPF across the enrolling centres and importantly reflects clinical practice, which we aimed to capture.

This study represents a fair and balanced approach to assessing the incidence of objectively measurable and treatable PF-ILDs in the UK. A rate of $14.5 \%$ of new referrals with non-IPF ILD is less than that reported in previous studies however our methodology is likely to give a more accurate result than estimates based on extrapolation from general disease statistics, from physician-reported estimates prone to significant biases, or insurance claim processes also substantially prone to bias. This information has implication for workforce planning and the funding of anti-fibrotic therapy in the UK and beyond.

\section{Refrences:}

1. Brown KK, Martinez FJ, Walsh SLF, Thannickal VJ, Prasse A, Schlenker-Herceg R, Goeldner R-G, Clerisme-Beaty E, Tetzlaff K, Cottin V, Wells AU. The natural history of progressive fibrosing interstitial lung diseases. Eur. Respir. J. 2020; 55: 1168-1170.

2. Cottin V, Hirani NA, Hotchkin DL, Nambiar AM, Ogura T, Otaola M, Skowasch D, Park JS, Poonyagariyagorn HK, Wuyts W, Wells AU. Presentation, diagnosis and clinical course of the spectrum of progressive-fibrosing interstitial lung diseases. Eur. Respir. Rev. 2018; 27: 180076.

3. Cottin V. Treatment of progressive fibrosing interstitial lung diseases: a milestone in the management of interstitial lung diseases. Eur. Respir. Rev. 2019; 28: 190109.

4. Flaherty KR, Wells AU, Cottin V, Devaraj A, Walsh SLF, Inoue Y, Richeldi L, Kolb M, Tetzlaff K, Stowasser S, Coeck C, Clerisme-Beaty E, Rosenstock B, Quaresma M, Haeufel T, Goeldner R-G, Schlenker-Herceg R, Brown KK, INBUILD Trial Investigators. Nintedanib in Progressive 
medRxiv preprint doi: https://doi.org/10.1101/2020.11.16.20229591; this version posted November 18, 2020. The copyright holder for this preprint (which was not certified by peer review) is the author/funder, who has granted medRxiv a license to display the preprint in It is made available under a CC-BY-NC-ND 4.0 International license .

Fibrosing Interstitial Lung Diseases. N. Engl. J. Med. 2019; 381: 1718-1727.

5. Olson AL, Gifford AH, Inase N, Fernández Pérez ER, Suda T. The epidemiology of idiopathic pulmonary fibrosis and interstitial lung diseases at risk of a progressive-fibrosing phenotype. Eur. Respir. Rev. 2018; 27: 180077.

6. Wijsenbeek M, Kreuter M, Olson A, Fischer A, Bendstrup E, Wells CD, Denton CP, Mounir B, Zouad-Lejour L, Quaresma M, Cottin V. Progressive fibrosing interstitial lung diseases: current practice in diagnosis and management. Curr. Med. Res. Opin. 2019; 35: 2015-2024.

7. Olson AL, Maher TM, Acciai V, Mounir B, Quaresma M, Zouad-Lejour L, Wells CD, De Loureiro L. Healthcare Resources Utilization and Costs of Patients with Non-IPF Progressive Fibrosing Interstitial Lung Disease Based on Insurance Claims in the USA. Adv. Ther. 2020; 37: 32923298.

8. Flaherty KR, Brown KK, Wells AU, Clerisme-Beaty E, Collard HR, Cottin V, Devaraj A, Inoue Y, Le Maulf F, Richeldi L, Schmidt H, Walsh S, Mezzanotte W, Schlenker-Herceg R. Design of the PF-ILD trial: a double-blind, randomised, placebo-controlled phase III trial of nintedanib in patients with progressive fibrosing interstitial lung disease. BMJ open Respir. Res. 2017; 4: e000212. 